\title{
Imigração e identidade étnica: a construção do "ser alemão" no Sul do Brasil
}

Immigration and ethnic identity: the construction of "being German" in southern Brazil

La inmigración y la identidad étnica: la construcción de "ser alemán" en el sur de Brasil

Rosane Marcia Neumann*

\section{Resumo}

$\mathrm{O}$ artigo trata da heterogeneidade presente no grupo étnico denominado no Brasil de alemães no Brasil. A formação de identidade étnica é sempre relacional, pois envolve a construção e a afirmação de um nós diante de um outro. Os imigrantes vindos em diferentes épocas e regiões da Alemanha, carregando suas peculiaridades, constituíram no Brasil sua identidade enquanto grupo étnico alemão, contrapondo-se aos outros. Internamente, porém, sobressaem as fragmentações, revelando um grupo étnico heterogêneo, caráter acentuado mais ainda em relação aos teuto-brasileiros. Busca-se elementos para entender como essas identidades étnicas são fluidas e acionadas nas relações cotidianas para se auto afirmar e diferenciar entre si, criando tensões e rupturas. Delimita-se como lócus para o estudo empírico da colônia privada e de colonização étnica alemã de Neu-Württemberg, na Primeira República, situada no município de Cruz Alta, região Noroeste do Rio Grande do Sul.

Palavras-chave: Imigração alemã. Relações étnicas. Colônia Neu-Württemberg.

\section{Introdução}

Os movimentos migratórios colocam em contato diferentes grupos étnicos em uma relação de alteridade, tanto frente a outros imigrantes, quanto aos nacionais. Outro aspecto a considerar são as próprias diferen-

Doutora em História/PUCRS. Professora do Programa de Pós-Graduação em História da Universidade de Passo Fundo/UPF. Pesquisadora do Núcleo de Estudos de História de Imigração (NEHI) do CNPq.

Recebido em 04/07/2013 Aprovado em 20/07/2013 http://dx.doi.org/10.5335/hdtv.14n.1.4168 
ças internas, isto é, grupos aparentemente homogêneos apresentam estratificações, podendo ser econômicas, de origem ou sociais, diferenças essas que emergem nas relações cotidianas. Lesser (2013) chama atenção que é comum que os estudos acadêmicos buscarem por conflitos étnicos ou por relações harmônicas, em que esses/essas não existem, ou não são percebidos como tais pelos elementos envolvidos. Ao tratar de tais questões, é preciso estar atentar à diferença entre os discursos dos grupos e suas ações, visto serem instâncias diferentes, pois nem sempre o discurso e a prática convergem. As identidades acionadas são flexíveis, ou, conforme define o autor, são um "fenômeno situacional", em que os indivíduos/grupos valem-se de múltiplas identidades, definindo seu pertencimento conforme os interesses em jogo.

Objetiva-se perceber empiricamente como o pertencimento étnico é negociado no cotidiano dos imigrantes alemães e de seus descentes, na relação interna do grupo e frente aos nacionais, descritos como "brasileiros" na Primeira República, tendo como espaço a colônia étnica alemã e particular Neu-Württemberg, situada no Noroeste do Rio Grande do Sul.

\section{Nós e os outros}

A e/imigração, para Sayad, é um fato social completo, pois há o emigrante, aquele que saiu de sua própria sociedade, e há o imigrante, aquele que chegou a uma terra de estranhos, e ambos são a mesma e única pessoa. $\mathrm{O}$ imigrante
[...] só existe na sociedade que assim o denomina a partir do momento em que atravessa suas fronteiras e pisa seu território; o imigrante "nasce" nesse dia para a sociedade que assim o designa (SAYAD, 1998, p. 16).

Para Pierre Bourdieu,

[...] o imigrante é atopos, sem lugar, deslocado, inclassificável. [...]. Nem cidadão nem estrangeiro, nem totalmente do lado do Mesmo, nem totalmente do lado do Outro, o "imigrante" situa-se nesse lugar "bastardo" [...], a fronteira entre o ser e o não-ser social (In: SAYAD, 1998, p. 11).

No local de chegada, os imigrantes buscam (re)construir suas identidades individuais e de grupos étnicos. A formação de identidade é sempre relacional, pois envolve a construção e a afirmação de um nós diante de um outro, ou seja, a alteridade se dá em relação a um outro. Desse modo,

[...] não apenas crio contraste em relação a um outro; crio um outro contrastivo. Crio contraste numa relação em que me vejo sendo visto por um outro que está se vendo sendo visto por mim (DAWSEY, 2005, p. 233-234).

Quando um indivíduo ou um grupo afirma-se como tal, o faz como meio de diferenciação em relação a um indivíduo ou a um grupo com que se defronta.

Para os imigrantes alemães no Sul do Brasil, o brasileiro representava o outro, frente ao qual construíram a sua identidade enquanto grupo étnico. Todavia, internamente, prevaleciam as diferenças entre os próprios grupos de imigrantes, oriundos de regiões distintas da Alemanha e de territórios ocupados pelos alemães em diferentes épocas, e em fluxo contínuo por mais de um século, carregando as marcas de sua origem. 
O que se tinha, então, era uma espécie de colcha de retalhos em que uma diversidade enorme de trajetórias se entrecruzava, movidas pelo estímulo da emigração, da busca de terra própria ou de liberdade em face dos constrangimentos políticos, sociais ou religiosos do "velho mundo" (WOORTMANN, 2000, p. 210).

Em meio à pluralidade, construíram como identidade comum o "ser alemão". Bairon Sant'anna afirma que a sustentação desse imaginário estava na "presença de uma ausência”, ou seja, "a presença da pátria-mãe no imaginário teuto-brasileiro na forma de pequenas narrativas metafóricas já que no campo simbólico ela está ausente" (1993/1994, p. 21-22). Aqui, a rememoração tornar-se-ia o sustentáculo da memória coletiva, cuja referência a qualquer objeto alemão remetia à pátria de origem, ou seja, nunca se fora tão apegado às tradições culturais do que na diáspora - nunca se havia sido tão alemão quanto no Brasil. Todavia, em terras brasileiras, esses grupos étnicos apresentavam formas de organização novas e adaptadas ao "aqui e agora", compartilhando de uma identidade, bem como de interesses econômicos e políticos (CUNHA, 1987).

Para Barth, a pertença étnica é, ao mesmo tempo, uma questão de origem, bem como de identidade corrente. Acresce, ainda, que o grupo étnico seleciona, dentro das suas características, as que são relevantes para a sua identificação e diferenciação em relação ao outro.

Se um grupo conserva sua identidade quando os membros interagem com outros, isso implica critérios para determinar a pertença e meios para tornar manifestas a pertença e a exclusão [...], a fronteira étnica canaliza a vida social - ela acarreta de um modo frequente uma organização muito complexa das relações sociais e comportamentais (1998, p. 195-196).

Por fim, Barth registra que as

[...] situações de contato social entre pessoas de culturas diferentes também estão implicadas na manutenção da fronteira étnica: grupos étnicos persistem como unidades significativas apenas se implicarem marcadas diferenças no comportamento, isto é, diferenças culturais persistentes (1998, p. 214).

\section{Relações étnicas no cotidiano da colônia}

Embora os imigrantes alemães fossem originários do território da Alemanha, a diferenciação sobressaía-se entre uma leva e a seguinte sobressaía, provocando conflitos e um distanciamento cultural a ser transposto. Assim, aqueles que já residiam no Brasil há várias gerações, que se identificavam como colonos ou teuto-brasileiros, eram vistos como aculturados e atrasados por aqueles recém chegado da Europa. A própria construção de uma identidade teuto-brasileira é complexa, pois, segundo Rambo, esse indivíduo considerava-se como

[...] teuto, porque vivia de acordo com os costumes, os hábitos, os valores e falava a língua de seus antepassados. Brasileiro, porque nascera em território brasileiro, como brasileiro fora registrado e como brasileiro se assumiu e agia (1999, p. 185).

Para Bairon Sant'anna,

[...] é possível compreender que a consciência tomada pelo teuto-brasileiro de si, torna seu ser cultural uma grande denegação. Ao identificar-se como teuto, denega o brasileiro e, ao dizer-se "brasileiro" denega o teuto. Sua "dupla identidade" 
aprofunda-se numa enorme crise com seu universo simbólico (1993/1994, p. 29).

A partir das relações, muitas vezes conflituosas e ásperas entre os alemães natos e os descendentes, formavam-se alguns estereótipos, difundidos tanto no imaginário popular quanto na imprensa.

Comparado ao alemão, o teuto-brasileiro é um trabalhador capaz e cioso de seu valor, com um intelecto pouco ágil e com visão limitada, dotado de pouco altruísmo, "cabeça-dura" e muito conservador, a quem frequentemente a forma interessa mais que o conteúdo, de maneira que quase se poderia dizer que ele cuida da escola mais por um instinto atávico do que movido por uma necessidade interna. Uma grande qualidade é a sua forte inclinação familiar associada com uma bem desenvolvida consciência racial. [O alemão] é intelectualmente mais vivaz e polivalente e mais aberto a novas ideias, de onde deriva que não raras vezes ele se ache ainda mais inteligente do que na realidade é e fique presunçoso. O ponto de vista do outro lhe parece sempre ultrapassado e ele - uma pessoa moderna e sem valores religiosos - o trata com superior condescendência. $\mathrm{O}$ amor à terra ainda lhe é estranho, os laços familiares não necessariamente sagrados (Kaiserlich Deutsches Konsulat apud. MEYER, [on-line]).

As relações intrincadas entre imigrantes alemães, teuto-brasileiros e nacionais figuravam na pauta de discussões da administração da Empresa de Colonização Dr. Herrmann Meyer, um empreendimento particular, de propriedade do alemão Dr. Herrmann Meyer ${ }^{1}$, com sede em Leipzig/ Alemanha, a qual instalou seu complexo colonial no Noroeste do Rio Grande do Sul, em 1897 , atuando na região até 1932 . O projeto de colonização tinha como objetivo inicial a formação de uma colônia étnica, essencial- mente com/para imigrantes alemães, onde pudessem ser e permanecer alemães, mantendo sua cultura de origem. Na prática, os imigrantes eram minoria, e no povoamento da colônia Neu-Württemberg (hoje, Panambi e Condor), colônia modelo da Colonizadora Meyer, situada no município de Cruz Alta, fundada em 1898, predominavam os migrantes internos, provenientes da antiga zona colonial do estado, com descendentes de alemães de segunda, terceira ou mais gerações. O agrupamento dessas populações em um mesmo espaço originou um mosaico cultural múltiplo, em que a categoria alemães reunia suabos, pomeranos, vestfalianos, além de austríacos, húngaros, teuto-russos, teuto-brasileiros, cada qual com seus costumes e suas tradições. Logo, era necessário construir uma identidade de neuwürttemberger, dentro dos parâmetros de alemães no exterior ou migrantes internos, negociando costumes e valores do lugar de partida e de chegada, retomando, ou mesmo inventando, uma tradição cultural comum (HOBSBAWN; RANGER, 1997), ou a própria regermanização daqueles já assimilados.

O elemento nacional não foi contemplado pelo empreendimento, sendo retirado gradualmente, conforme a aquisição de novas glebas de terras. Porém, as relações entre o grupo étnico alemão e os nacionais (proprietários de terras, autoridades, caboclos), domiciliados nas cercanias da colônia, não implicou maiores problemas, conforme o discurso da Colonizadora Meyer, limitando-se à prestação de serviços à empresa e troca de saberes. Por exemplo, aconselhava-se o imigrante a contratar serviços de um caboclo para a derrubada das matas e a construção da casa, tendo 
em vista que conheciam as madeiras e as técnicas pertinentes, "porque o novo imigrante entende pouco ainda desse trabalho e pode estragar muito" (MEYER, 1906, p. 4).

Projetos de colonização étnica, como proposto por Meyer, em pleno início da Primeira República, foram bem recebidos pela ala germanista no estado, enquanto criticavam a formação de colônias mistas, pela sua despreocupação com questões étnicas e confessionais, comprometendo o desenvolvimento como um todo. Dentre os maiores críticos, estavam os jesuítas católicos, envolvidos diretamente na assistência religiosa da zona colonial alemã e italiana e ligados ao Bauernverein ${ }^{2}$, os quais defendiam, abertamente, a colonização confessional e étnica, tendo como seus expoentes os padres jesuítas Theodor Amstad, João Evangelista Rick e Max von Lassberg. De acordo com Amstad,

[...] a mistura étnica e confessional se constitui num dos grandes males das atuais colonizações do governo [republicano]. Em não poucos casos, põe-se em prática uma ação planejada nesse sentido, visando, como se diz, a estimular a formação de "um tipo brasileiro uniforme". Como consequência desse sistema, os elementos melhores e mais bem dotados abandonam as "colônias misturadas" e vão fixar-se em colônias de associações nas quais se pratica a colonização étnica e confessionalmente identificada (Cem anos de germanidade..., 1999, p. 51).

Na avaliação do padre jesuíta Balduíno Rambo,

[...] não demorou para ficar claro que era preciso separar não só por confissões como também por nacionalidades. As colônias mistas de alemães, italianos e poloneses não logravam organizar uma vida comunitária como era de desejar. Em muitos casos o segmento mais fraco migrava para outro lugar, fato que criava também sérios obstáculos para o desenvolvimento econômico (In: RAMBO; RABUSKE, 2004, p. 58).

Inspecionar e observar, comparativamente, a formação e o desenvolvimento de uma colônia étnica e de uma colônia mista na região do Planalto Rio-grandense, respectivamente, Neu-Württemberg e Ijuí, foi o objetivo do representante do consulado da Alemanha em Porto Alegre, de sobrenome Reinhardt, produzindo como documento conclusivo um Relatório datado de 20 de julho de 1921. Como aspectos relevantes, destacou como primeiro ponto: Ijuí, enquanto colônia pública recebeu ajuda oficial, os lotes foram ocupados sistematicamente, e um ramal da linha férrea foi prolongado até a sede da colônia, além de servir, estrategicamente, como um marco adiantado para impedir o avanço argentino. Do outro lado, Neu-Württemberg somente obteve apoio passivo do governo, sendo todo o trabalho realizado pelo diretor da colônia e algumas parcerias com o Intendente de Cruz Alta; e, a linha férrea passava a uma longa distância da sede da colônia. Segundo ponto: as duas colônias progrediram, mas Neu-Württemberg permaneceu alemã na sua configuração externa, assim como o caráter de seus habitantes; já Ijuí, primeiro sob a administração do Dr. Augusto Pestana, seguido por Antônio Soares de Barros, havia transformado-se em um "centro colonial internacional", onde o elemento nacional (Lusobrasilianertum) foi colocado ao lado dos imigrantes (alemães, poloneses, italianos, russos e suecos) para acelerar a sua assimilação. Assim sendo, 
Neu-Württemberg é um piece de résistance do Deutschtum [germanidade] nesse Estado; ali o espírito alemão se manifesta muito vigoroso, e tem tamanha força, que podemos falar de uma regermanização da população de origem alemã, que fala um alemão legítimo, sem preencher por termos abrasileirados. Essa regermanização mostra-se claramente junto àqueles que remigraram das colônias velhas de Santa Cruz, Teutônia, São Leopoldo, etc., onde em grande medida haviam se tornado brasileiros e se juntaram à colônia, onde, sob a influência dos Neu-Württemberger, novamente se emanciparam. No seu atual estado, a colônia é a obra singular de um homem, o diretor Hermann Faulhaber ${ }^{3}$ e de sua esposa. Primeiro, ele foi pastor, mas conscientemente abandonou seu ofício religioso; esse distinto suabo, desde o princípio, assumiu seu trabalho aqui não como comerciante, mas como colonizador em sentido cultural, com sua grande integridade, habilidade e praticidade, ele foi um dos primeiros - sim, eu não hesito em dizer - o primeiro e distinguido propagandista do Deutschtum neste Estado e talvez em todo sul do Brasil; mesmo sendo muito culto, permaneceu um homem simples, atuando como fator de cultura sob a extensa área colonial de Neu-Württemberg, bem como além de seus limites. O melhor e o mais simpático nele é que ele mesmo nem sabe disso. Como mostra a experiência, aqueles que se fixam nos centros urbanos aceitam mais rapidamente o caráter luso-brasileiro. Contudo, Faulhaber esforça-se para preservar a cultura alemã na sua aldeia. Até agora, ele foi bem sucedido (grifo no original). ${ }^{4}$

Reinhardt concluiu seu relatório apontando a Serra como "o lugar onde o Deutschtum se mantinha e avançava, mais do que em outros lugares. Um lugar alemão". Essa era a imagem da colônia vista por alguém de fora. ${ }^{5}$
Os anuários e jornais também contribuíram para a construção de uma imagem coerente e positiva da colônia Neu-Württemberg, olhando-a de fora e colocando-a em circulação para diferentes públicos-leitores. Em linhas gerais, reafirmavam o discurso oficial da Colonizadora Meyer, comprovando, com depoimentos de seus editores, com fotografias, artigos e notícias, que Neu-Württemberg era e permanecia uma autêntica colônia alemã-modelo. Reforçaram tratar-se de uma colônia privada para agricultores e, secundariamente, para artesãos, mas somente aqueles que realmente estavam dispostos a se sujeitar a esse modo de vida deveriam (e)migrar. Não se tratava de uma propaganda suntuosa, como aquela do século XIX, a qual representava o Brasil e suas colônias como uma terra de possibilidades ilimitadas. Essas publicações colaboraram, ainda, para tornar conhecidos o Noroeste do estado e as suas colônias, indicando-as como mais uma opção para a realocação de excedentes populacionais.

Outro tipo de evento que merecia destaque e delinea a projeção desse núcleo colonial era a visita de autoridades alemãs, como em 1913, do Barão de Lindequist, ex-ministro das colônias da Alemanha na África, que chegou acompanhado pelo Dr. José Watzl, funcionário do Ministério da Agricultura do Brasil, destacado pelo governo brasileiro, o qual permaneceu na colônia por três dias. Na companhia do diretor da Colonizadora Meyer, visitou vários colonos, “com os quais palestrou amistosamente, colhendo em toda a parte informações, tendo, daquilo que viu e ouviu, recebido as mais agradáveis impressões possíveis" ${ }^{6}$ Em seu discurso de 
saudação ao Barão, Minoly Gomes Amorim 7 expressou sua expectativa futura em relação a essa visita, ressaltando a contribuição dos alemães para o desenvolvimento da colônia e a ausência de conflitos étnicos:

[...] o alto testemunho, a observação insuspeita daquilo que somos, do modo que aqui vivem e da consideração e justo prestígio de que entre nós gozam os compatriotas de S. Excia.

Muito tem se escrito e muito tem sido dito, cá e lá, referentemente às cousas desta terra; mas a palavra de S. Excia, estamos certos, será a expressão fiel da própria observação, do que viu e ouviu nos longos dias passados na modesta convivência dos nossos bons colonos alemães, nas clareiras das nossas imensas matas virgens e na roça, onde verdeja o milharal.

Esta colônia é bem uma prova do que são as demais colônias alemãs deste Estado: prósperas e felizes, parece que em todas elas sorri a harmonia doce e sossegada da vida e do trabalho.

A civilização, que da vossa grandiosa Alemanha tem, continuamente, se deslocado para o nosso país, vai, pouco a pouco, penetrando em todas as roças, através dos pampas, além das serranias, e em toda a parte confraternizam-se alemães e brasileiros... ${ }^{8}$

Em 21 de maio de 1914, a colônia Neu-Württemberg recebeu a visita de dois representantes da Alemanha: o Cônsul Freiherr von Stein e o Propost Braunschweig. Após recepção, discursos e apresentação de alunos, realizaram várias excursões pelo interior da colônia, visitando os principais estabelecimentos industriais e escolares. Os visitantes teriam classificado a colônia como modelar, elogiando a administração de Faulhaber. Ao cumprimentar os visitantes, Minoly Gomes Amorim, representando na ocasião o Inten- dente Municipal Cel. Firmino Paula Filho, fez as melhores referências aos alemães,

[...] colaboradores do progresso do nosso país, estreitamente ligados aos brasileiros na obra do engrandecimento e prosperidade da nossa nacionalidade, não existindo, entre uns e outros, rivalidades de raça, religião ou mal entendido patriotismo, mas sim união completa, sendo a única luta existente a do trabalho, mas o trabalho que dignifica o homem, a pátria e a família. ${ }^{9}$

Financeiramente, a Colonizadora Meyer foi um fracasso, visto que os investimentos ultrapassaram em muito os lucros auferidos. Por essa razão, todo esforço foi canalizado para o trabalho cultural que, segundo Meyer,

[...] se, daqui a alguns anos, pudermos abandonar Neu-Württemberg à sua própria sorte, sentiremos a imensa satisfação de termos realizado, lá, um bom trabalho cultural e de havermos criado uma colônia modelar no país. E, por ser colônia pequena, maior será seu valor intrínseco (MEYER apud FAUSEL, 1949, p. 30). ${ }^{10}$

Atendendo aos propósitos de Meyer, a colônia deveria permanecer alemã e, por extensão, os imigrantes precisavam acatar a essas prerrogativas. ${ }^{11}$ Em 1903, diante da insistência do administrador Horst Hoffmann de atrair poloneses para a colônia, Meyer assegurou: "meu propósito não é colocar outras nacionalidades em Neu-Württemberg, só alemães. Além disso, conheço os poloneses como maus colonos - ou só o lado ruim do colono". ${ }^{12}$ Em nível de gerência da Colonizadora Meyer, havia como ordem enviar, sempre que possível, as famílias alemão-polonesas para a colônia Xingu, de propriedade da empresa, situada no município de Palmeira das Missões. ${ }^{13}$ 
Entretanto, a relação entre os indivíduos do grupo étnico alemão, vista de dentro, era complexa. Em 1899, ao efetuar um empréstimo a um imigrante alemão para retornar à Alemanha e buscar a sua família, o administrador da Colonizadora Meyer justificou o fato alegando que enquanto viveu ao "modo alemão", acabou por se endividar, mas, que já havia se ajustado ao modo de vida da colônia - ao contrário de seu irmão, que não servia para ser colono. ${ }^{14}$ Por sua vez, o pastor Hermann Faulhaber, imigrante de Württemberg, ao assumir o pastorado na colônia em 1902, considerou-a em completo desleixo religioso e educacional. Suas primeiras medidas confluíram para resgatar as raízes da cultura alemã, objetivando nivelar culturalmente os teuto-brasileiros aos imigrantes recém-chegados.

Essas questões étnicas perpassavam o cotidiano das famílias, atingindo, por vezes, as próprias instituições das quais participavam. Em $1^{\circ}$ de março de 1903, realizou-se a primeira assembleia dos colonos da colônia Neu-Württemberg, com o propósito de fundar um Bauernverein. Já em 15 de março de 1903, houve uma segunda assembleia, constituindo oficialmente o Bauernverein, com 35 sócios, elegendo a primeira diretoria e uma comissão para a elaboração dos estatutos. A entidade deveria preocupar-se com as questões dos agricultores, desempenhar uma função cooperativista de interesse dos colonos e filiar o núcleo de Neu-Württemberg à Associação Rio-Grandense de Agricultores, o Riograndenser Bauernverein. A fundação dessa associação e os seus princípios foram bem vistos por Herrmann Meyer, pois contribuiriam para o desenvolvimento da co- lônia, porém, a administração da empresa deveria estar atenta aos rumos assumidos pela entidade e por seus dirigentes e, se necessário, intervir.

Um ano depois, já se esboçava uma dissidência dentro do Bauernverein, que, conforme o relatório do pastor Hermann Faulhaber, era perceptível há mais tempo. Formaram-se, então, dois grupos: o primeiro, composto pelos velhos colonos, os quais não demonstravam muito interesse pela entidade, participavam pouco das reuniões,quase não se manifestavam e eram vistos como mais reservados; o segundo grupo, era integrado pelos Deutschländer ou imigrantes da Europa e por aqueles provenientes de cidades brasileiras maiores, que participavam de todas as reuniões, manifestavam-se e tinham ideias de cooperativismo em vista, descritos como mais progressistas. Gradualmente, esse segundo grupo assumiu a liderança, fazendo prevalecer as suas aspirações. Em 11 de setembro de 1904, o grupo da situação/colonos, composto por Rogge, Restel, Hegner e Baumgart, foi derrotado na eleição da nova direção, recebendo apenas um terço dos votos. Dos sessenta agricultores então membros da entidade, apenas dois terços estavam presentes, predominando o grupo da oposição/Deutschländer. Assim foi fundada a Produktions-und Bezugsgenossenschaft [Cooperativa de Produção e Compras da Associação de Agricultores de Neu-Württemberg], subordinada ao Bauernverein e que aceitava apenas os sócios desse. É evidente que no grupo dos Deutschländer havia alguns colonos, e, no dos colonos, alguns imigrantes, como von Braun. Mas, de modo geral, a divisão era clara, como tam- 
bém ficava evidente que as ideias de cooperativismo predominavam entre os imigrantes, que acabaram fundando a cooperativa, a qual tinha como objetivo principal comprar os produtos dos colonos, no caso o tabaco, e vender-lhes os produtos necessários ao seu consumo. ${ }^{15}$

Nesse mesmo contexto, observando a configuração populacional da colônia de Neu-Württemberg e o comportamento dos imigrantes nesse meio, o pastor Hermann Faulhaber anotou, em inícios de 1903:

Quase metade dos nossos camponeses são "velhos colonos" [alte Kolonisten], acostumados à vida e ao trabalho na floresta, a maioria já nascidos no Brasil ou imigrados bem jovens. Eles vieram em sua maioria da antiga zona colonial da região leste do estado, em busca de terras baratas e lugar para ter os seus filhos. Eles têm como característica ser individualistas, independentes e autoconsciente, mais do que nossos camponeses lá [na Alemanha]. Eles são independentes, pelo menos em relação ao Estado, à Igreja, ao jornal, ao partido político, apesar de toda sua simplicidade são reis livres em sua terra. Aproximadamente $1 / 4$ de nossos colonos são compostos de pessoas, que como artesãos (Handwerker) imigraram há anos, e em Porto Alegre ou outro lugar qualquer, exerciam o seu ofício, mas em decorrência da depressão econômica dos últimos anos, foram forçados a tornarem-se colonos: funileiro, serralheiro, sapateiro, marceneiro, ourives. Eles não sabem trabalhar tão bem como os velhos colonos, mas são bem ágeis. Até onde a situação permite, eles exercem paralelo ao seu trabalho agrícola o seu ofício. E só os alemães recém-chegados (Deutschländer) imigraram há pouco. Entre eles, há vários tipos humanos misturados. Eu lembro de dois jovens instruídos, agricultores de lá [Alemanha], solteiros, os quais estão morando juntos em uma tenda de cigano. Vie- ram com todo tipo de teoria de agricultura para cá, e devido à quebra do arado e de outros experimentos, não plantaram nada ao longo deste ano que eles aqui se encontram; e apesar disso, se sentem homens importantes e regularmente vem a cavalo, com rostos sérios, para o Stadtplatz para comprar pão, fazer contato com os demais e saber dos últimos acontecimentos! Ao ver as suas figuras, muitas vezes lembro dos rapazes que brincam de "Urwälder"! Todavia, são pessoas simpáticas e eu gosto de vê-los na casa pastoral. Recentemente veio um eletrotécnico de Berlin com grande família, e era até então diretor de uma grande fábrica, e então perdeu toda sua fortuna, e procura aqui agora sua salvação. Um autêntico berlinense: "agora eu venho, agora tudo vai mudar aqui! Até agora não tinha ninguém aqui ainda que pudesse fazer algo por essas pessoas. Isso vai mudar. E uma festa de Natal bem diferente nós teremos da próxima vez, não mais demoradas velas de cera, mas sim lâmpadas elétricas. Isso vai impressionar as pessoas! Elas vão arregalar os olhos com isso!" Agora ele está lá no meio da floresta e provavelmente está trabalhando na sua plantação. E na colônia tudo está como antes... Outros, após ter enterrado as ilusões que trouxeram, logo se encontram bem aqui, como um Stuttgarter com família, até então empacotador em uma livraria; um marceneiro de Brettach; um eletrotécnico de Stuttgart com esposa, um Siebenbürger com família camponesa veio recentemente. Também não quero esquecer daqueles que, após uma curta estada, partiram novamente, porque a vida na floresta, uma vez experimentada, era bem diferente daquela que eles haviam imaginado. Trabalho e não pombas assadas voando, pequeno camponês e nenhuma salvação! [...]. O destino desses que vem para a colônia e em breve já jogam o machado e a enxada para o lado é, na maioria, difícil e triste! Muitos passam a beber cachaça, e acabam morrendo na beira de alguma estrada. Por isso, nunca é demais insistir: só 
pessoas que são acostumadas a pesados trabalhos braçais e têm alguma experiência, como nossos pequenos camponeses, ou um ofício, podem, depois de superadas as dificuldades iniciais, conquistar aqui uma existência satisfatória. Outros só com raras exceções (FAULHABER apud FAULHABERSTIFTUNG, 1933, p. 14-15).

Percebe-se, no relato, a emergência das identidades regionais do local de origem e as representações construídas em torno delas, acionadas quando essas populações eram colocadas em contato. Assim, ao reduzir a escala de análise, a diferença torna-se visível, embora, para o meio externo, construíram sua identidade étnica enquanto alemães, dando a ideia de tratar-se de um grupo homogêneo. Essas fricções entre colonos teuto-brasileiros e imigrantes alemães tornaram-se salientes na década de 1920, quando a colônia Neu-Württemberg recebeu um grupo de mais de 600 imigrantes alemães, em sua maioria suabos e urbanos, atingidos direta ou indiretamente pela I Guerra Mundial, muitos dos quais profissionais liberais e técnicos. Conforme os discursos locais, os imigrantes viam-se culturalmente superiores, dedicando-se à fundação de indústrias. Já os colonos, descreviam os imigrantes como arrogantes e ignorantes, por desconhecer a forma de derrubar a mata e de praticar a agricultura, cometendo inúmeros erros e causando prejuízos. No vocabulário cotidiano da colônia, os termos Kolonist (colono) e Deutschländer delimitam, claramente, as identidades de dois grupos em oposição, embora tratassem do mesmo grupo étnico (cf. NEUMANN, 2009).

A organização social da colônia é definida como "solidariedade étnica" por Ro- che (1969), na qual o papel da família, como célula de organização e sobrevivência, foi transferindo-se para a Picada ou Linha e para a Colônia, em um processo doloroso, mas necessário. Para Tramontini, esse mundo colonial que se estruturava precisava dar conta de sua organização interna enquanto grupo, e externa, frente à sociedade brasileira, para superar problemas e adversidades, bem como conquistar seu espaço. Esse autor entende os conflitos "como parte da dinâmica de implementação do projeto de colonização, de inserção dos imigrantes na sociedade brasileira, e como situação de organização do próprio grupo social, no qual a etnicidade assume clara afirmação social e política" (2004, p. 117). Ainda conforme ele, para o início do século XIX, é preferível o emprego do termo

[...] "organização social" com base étnica à 'identidade étnica', uma vez que o grupo imigrante ainda não erigira uma fala, um discurso ou imagem sobre si próprio, ou atribuíra legitimidades aos seus "representantes" (TRAMONTINI, 2004, p. 119).

Nas colônias novas, percebe-se as fricções entre teuto-brasileiros, já com um discurso étnico definido, e imigrantes alemães, complexificando as relações.

Portanto, os imigrantes alemães constroem em solo brasileiro sua identidade e seu discurso étnico para relacionarem-se com os outros, representando um grupo étnico homogêneo, mas, internamente, preservam múltiplas identidades, ligadas ao local de origem, à cultura, à situação socioeconômica, política, religiosa, tudo isso praticado por alemães natos ou descendentes... A produção historiográfica dedica-se, em primei- 
ra linha, às relações interétnicas estabelecidas entre os imigrantes alemães e os outros, representados pelo elemento nacional. Todavia, o estudo sobre a fragmentação interna no que se define como grupo étnico alemão, ainda está por ser realizado, mapeando as relações entre as minorias presentes entre os imigrantes de origem alemã quando colocados em contato com o exterior, e desses para com os teuto-brasileiros.

\section{Abstract}

The present article deals with the heterogeneity in the ethnic group called the Germans in Brazil. The formation of ethnic identity is always relational, because it involves the construction and affirmation of us in front of another. Immigrants in different times and regions of Germany, carrying their peculiarities, in Brazil constituted his identity as a German ethnic group, opposing each other. Internally, however, stand the fragmentations, revealing a heterogeneous ethnic group, even more marked character in relation to the German-Brazilians. We seek to understand how these elements to ethnic identities are fluid and driven in everyday relationships, to affirm and differentiate themselves from each other, creating tensions and ruptures. Is delimited as a locus for the empirical study the private ethnic German colony and colonization of Neu-Württemberg, in the First Republic, located in Cruz Alta, the northwest region of Rio Grande do Sul.

Keywords: German immigration. Ethnic relation. Colony Neu-Württemberg.

\section{Resumen}

El articulo trata de la heterogeneidad presente en el grupo étnico denominado de alemanes en Brasil. La formación de la identidad étnica es siempre relacional, pues envuelve la construcción y afirmación de un nosotros delante de uno otro. Los inmigrantes venidos en distintas épocas y regiones de Alemania, trayendo sus peculiaridades, constituyeron en el Brasil su identidad como grupo étnico alemán, en contradicción a los otros. Internamente, todavía, sobresalen las fragmentaciones, revelando un grupo étnico heterogéneo, característica aún más acentuada en relación a los "teuto-brasileiros". En este texto, se busca elementos para entender como estas identidades étnicas son fluidas y accionadas en las relaciones cotidianas, para la auto afirmación y diferenciación interna, criando tensiones y rupturas. El locus delimitado para el estudio empírico es la colonia privada y de colonización étnica alemana de Neu-Württemberg, en la Primera República, ubicada el municipio de Cruz Alta, región noroeste de Rio Grande do Sul.

Palabras clave: Inmigración alemana. Relaciones étnicas. Colônia Neu-Württemberg.

\section{Notas}

1 Heinrich August Herrmann Meyer nasceu em 11 de janeiro de 1871, em Hildburghausen, no estado da Turíngia, Alemanha. Na sua formação acadêmica, estudou geografia e etnologia nas universidades de Strassburg, Berlin e Jena. Obteve seu título de Doutor [Doktor der Philosophie] em 1895, na Universidade de Jena, ao defender a tese Bogen und Pfeil in Central-Brasilien. Ethnographische Studie [Arco e Flecha no Brasil-Central. Um estudo etnográfi- 
co]. Seu objeto de estudo - a cultura indígena do Brasil central - e sua abordagem o aproximou dos pesquisadores americanistas. Para aprofundar seus conhecimentos e coletar material empírico, Meyer organizou duas expedições à região das nascentes do rio Xingu, no estado do Mato Grosso. A primeira expedição, de fevereiro de 1896 a janeiro de 1897 e, a segunda expedição, de janeiro de 1899 a novembro de 1899. A terceira e última viagem ao Brasil foi por conta de seu projeto de colonização, acompanhado de sua esposa, Else Meyer, entre 10 de setembro de 1900 e 10 de janeiro de 1901. Herrmann Meyer era sócio proprietário do Instituto Bibliográfico de Leipzig, Alemanha e investiu no sul do Brasil por meio de sua Empresa de Colonização Dr. Herrmann Meyer, em um projeto de colonização, adquirindo para isso terras de particulares, revendendo-as, posteriormente, no formato de lote colonial (25 ha). Fundou em Palmeira das Missões as colônias Xingu [Novo Xingu] (1897), Erval Seco (1899) e posse Boi Preto (1899); em Cruz Alta, a colônia Neu-Württemberg [Panambi] (1898), e a posse Castilhos (1903), em Júlio de Castilhos. Meyer faleceu em 17 de março de 1932, em Leipzig (Cf. NEUMANN, 2009).

2 O Bauernverein - Associação dos Agricultores - foi fundado no II Katholikentag ( $2^{\circ}$ Congresso Católico) realizado em Feliz (RS), em 1900, e seus objetivos direcionavam-se, principalmente, aos problemas econômicos e técnicos dos agricultores. Uma das principais ideias defendidas pela associação era o cooperativismo. Seu idealizador foi o padre jesuíta Theodor Amstad. Pelos os estatutos, essa associação foi pensada como uma organização interétnica e interconfessional. As pretensões, portanto, não se limitavam, apenas, à solução dos problemas dos teuto-brasileiros católicos. Tratava-se de um projeto de promoção humana que não deveria excluir nenhuma das vertentes étnicas ou religiosas presentes no estado. O Bauernverein fundou a colônia Serro Azul (Cerro Largo), em 1902. Já em 1912, na assembleia dos católicos em Venâncio Aires, houve uma divisão, e foi fundada a Volksverein für die Deutschen Katholiken in Rio Grande do Sul (Sociedade União Popular para os Católicos Alemães do Rio Grande do Sul), também idealizada pelo padre Theodor Amstad SJ., logo, de caráter confessional, enquanto os protestantes continuaram com o Bauernverein, sob a designação de Liga Colonial (cf. RAMBO, 1992; SCHALLENBERGER, 2001).

3 Em 1902, o pastor protestante Herrmann Faulhaber e sua esposa Marie Faulhaber, professora, foram contratados na Alemanha pela Coloniza- dora Meyer para assumir a assistência religiosa e educacional na colônia Neu-Württemberg e Xingu. Contudo, em 1908, Faulhaber abandonou o pastorado e assumiu a administração da Colonizadora, cargo no qual permaneceu até 1926, quando de seu falecimento. Paralelamente, exerceu a administração da rede escolar particular local. Já Marie Faulhaber foi atuante tanto na escola quanto na igreja, mas sem jamais ser remunerada para tais funções (cf. NEUMANN, 2009).

4 No documento não consta o prenome de Reinhardt, nem fica explícita a sua função no consulado (Relatório de Reinhardt, fl. 3-4. Deutsches Konsulat in Porto Alegre à Deutsche Gesandtschaft, no Rio de Janeiro e ao Auswärtiges Amt, Berlin, Porto Alegre, 20/7/1921. R- 79001 a 05. Das Politische Archiv des Auswärtigen Amts. Berlin, Alemanha). Tradução livre da autora.

5 Os diretores da colônia Neu-Württemberg e a direção da Colonizadora Meyer tinham como preocupação manter seu perfil enquanto colônia alemã, mas sem se aproximar das discussões pangermanistas, ou buscar qualquer vínculo político com a Alemanha.

6 Discurso manuscrito de Minoly Gomes Amorim, 1913. Álbum de recortes de jornais de Minoly Gomes Amorim, 1906-1923. MAHP- Museu e Arquivo Histórico Professor Hermann Wegermann, Panambi).

7 Em fevereiro de 1906, a municipalidade de Cruz Alta instalou na colônia uma escola pública, nomeando como professor o Capitão Minoly Gomes Amorim, filho da elite estancieira cruzaltense. Em uma carreira ascendente, em 1913 foi nomeado como subdelegado de Neu-Württemberg, e também foi o primeiro subintendente da colônia, nomeado para tal cargo em 11 de abril de 1916. Uma vez eleito para o Conselho Municipal, renunciou ao cargo da subintendência e da subdelegacia. Entre 1907 e 1922, vários artigos de sua autoria foram publicados na imprensa republicana de Cruz Alta, reunidos pelo autor em formato de Álbum de recortes. Acrescenta-se a eles, ainda, uma série de discursos pronunciados em saudação a autoridades e visitantes em geral na colônia e, posteriormente, no Conselho Municipal (Álbum de recortes de jornais de Minoly Gomes de Amorim, 1906-1923. MAHP).

8 Discurso manuscrito de Minoly Gomes Amorim, 1913. Álbum de recortes de jornais de Minoly Gomes Amorim, 1906-1923. MAHP.

9 Nota de Minoly Gomes Amorim no jornal Cruz Alta, 4/6/1914. Álbum de recortes de jornais de Minoly Gomes Amorim, 1906-1923. MAHP. Cabe retomar a afirmação de Lesser (2013), de que o discurso e a ação são distintos. Aqui, a contribui- 
ção econômica dos imigrantes alemães e seus descendentes, vinculada ao trabalho são ressaltados, e o perfil de colônia étnica positivado. Já durante o Estado Novo (1937-1945), com a campanha de nacionalização do governo de Getúlio Vargas, a colônia foi classificada como um quisto étnico, cuja nacionalização era urgente, e os conflitos étnicos, até então velados ou inexistentes, emergiram, reforçando as fronteiras entre os nacionais e os alemães, nesse caso, afetando indistintamente os imigrantes alemães e os teuto-brasileiros (cf. NEUMANN, 2003).

10 Em 14 de maio de 1931, Herrmann Meyer recebeu a maior comenda de honra do Deutsches Ausland-Institut, o Deutscher Ring [anel alemão], em reconhecimento pela fundação de Neu-Württemberg e o trabalho realizado em defesa do Deutschtum no exterior (FAULHABERSTIFTUNG, 1933).

11 Carta. Leipzig, 29/9/1901. Herrmann Meyer a Horst Hoffmann, Porto Alegre. Pasta Carta Herrmann Meyer a Horst Hoffmann, Caixa 42, MAHP

12 Carta. Leipzig, 2 e 4/3/1903. Herrmann Meyer a Horst Hoffmann, Porto Alegre. Pasta Carta Herrmann Meyer a Horst Hoffmann, Caixa 42, MAHP.

13 Relatório 5-7. De 1/3 a 15/4/1903. Porto Alegre, 18/04/1903. Horst Hoffmann a Herrmann Meyer, Leipzig. Pasta Transcrição Livro Copiativo 44, Caixa 109, MAHP.

14 Carta. Cruz Alta, 19/9/1899. Carlos Dhein a Herrmann Julius Meyer, Caixa 63, MAHP.

15 Relatório de Hermann Faulhaber. Elsenau, 6/10/1904. Livro Copiativo n. 11, Fl. 251-252, MAHP.

\section{Referências}

BAIRON SANT'ANNA S. B. O Fantasma da unidade cultural na metáfora palinódica do brasileiro alemão. Revista História, São Paulo, n. 129-131, p. 19-30, ago-dez/1993 a ago-dez/1994.

BARTH, F. Grupos étnicos e suas fronteiras. In: POUTIGNAT, P. Teorias da etnicidade: grupos étnicos e suas fronteiras. São Paulo: UNESP, 1998.

Cem anos de germanidade no Rio Grande do Sul 1824-1924. São Leopoldo: UNISINOS, 1999.

CUNHA, M. C. Antropologia do Brasil. Mito, história, etnicidade. 21. ed. São Paulo: Brasiliense, 1987.
DAWSEY, J. C. (Org.). Americans, imigrantes do velho Sul no Brasil. Piracicaba: Editora UNIMEP, 2005.

FAULHABERSTIFTUNG. Neu-Württemberg. Eine Siedlung Deutscher in Rio Grande do Sul Brasilien. Stuttgart (Alemanha): Ausland-und Heimat Verlags A.-G., 1933.

FAUSEL, E. Cinqüentenário de Panambi 18991949. s. 1.: s.ed., 1949.

HOBSBAWN, E; RANGER, T. (Org.). A invenção das tradições. 2. ed. Rio de Janeiro: Paz e Terra, 1997.

LESSER, J. Repensando identidade nacional: novas metodologias para os estudos de imigrantes e etnicidades no Brasil. Oficina ministrada no II Congresso Internacional de História Regional, UPF, 2013.

MEYER, D. E. E. "Alemão", "estrangeiro" ou "teuto-brasileiro"? Disponível em: <http://www.anped. org.br/0219t.htm>. Acesso em: 18 out. 2001.

MEYER, H. Ackerbaukolonien. Neu-Württemberg und Xingu in Rio Grande do Sul (Südbrasilien). Leipzig: Bibligraphischen Institut, 1906.

NEUMANN, R. M. Uma Alemanha em miniatura: o projeto de imigração e colonização étnico particular da Colonizadora Meyer no noroeste do Rio Grande do Sul (1897-1932). 2009. v. 2. Tese (Doutorado em História) - Faculdade de Filosofia e Ciências Humanas, PUCRS, Porto Alegre, 2009.

"Quem nasce no Brasil é brasileiro ou traidor!". As colônias germânicas e a campanha de nacionalização. 2003. Dissertação [Mestrado em História]. História da América Latina. Programa de Pós-Graduação em História UNISINOS, São Leopoldo, 2003.

RAMBO, A. B. A identidade teuto-brasileira em debate. Estudos ibero-americanos. Porto Alegre: PUCRS, v. XXV, n. 2. dez. 1999.

A Sociedade União Popular. Perspectiva Econômica, v. 27, n. 79. Série Cooperativismo, n. 32., 1992. 
RAMBO, A. B.; RABUSKE, A. Pe. João Evangelista Rick, SJ. Cientista, colonizador, apóstolo social, professor. São Leopoldo: Editora Unisinos, 2004.

ROCHE, J. A colonização alemã e o Rio Grande do Sul. Porto Alegre: Ed. Globo, 1969.

SAYAD, A. A imigração. São Paulo: Edusp, 1998.

SCHALLENBERGER, E. O associativismo cristão no sul do Brasil - a contribuição da Sociedade União Popular e da Liga das Uniões Coloniais para a organização e o desenvolvimento social sul-brasileiro. Porto Alegre, 2001. Tese (Doutorado em História). Programa de Pós-graduação em História, PUCRS, 2001.

TRAMONTINI, M. J. Identidade relacional: uma abordagem sobre a construção da identidade étnica dos imigrantes alemães no Sul do Brasil. In: SIDEKUM, A. (Org.). Às sombras do carvalho. São Leopoldo: Nova Harmonia, 2004. p. 115-128.

WOORTMANN, E. F. Identidades e memória entre teuto-brasileiros: os dois lados do Atlântico. Horizontes antropológicos, Porto Alegre, UFRGS/IFCH, n. 14. p. 177-204, nov. 2000. 